\title{
Tropospheric New Particle Formation and the Role of Ions
}

\author{
Jan Kazil • R. Giles Harrison • Edward R. Lovejoy
}

Received: 30 December 2007 / Accepted: 29 May 2008 / Published online: 17 June 2008

(C) Springer Science+Business Media B.V. 2008

\begin{abstract}
Aerosol particles play an important role in the Earth's troposphere and in the climate system: They scatter and absorb solar radiation, facilitate chemical processes, and serve as condensation nuclei for the formation of clouds. Tropospheric aerosol particles are emitted from surface sources or form in situ from the gas phase. Formation from the gas phase requires concentrations of aerosol precursor molecules aggregating to form molecular clusters able to grow faster than they evaporate. This process is called nucleation. Gas phase ions can reduce the concentration of aerosol precursor molecules required for nucleation, as they greatly stabilize molecular clusters with respect to evaporation. Therefore, ions are a potential source of aerosol particles. Since atmospheric ionization carries the signal of the decadal solar cycle due to the modulation of the galactic cosmic ray intensity by solar activity, a possible connection between the solar cycle, galactic cosmic rays, aerosols, and clouds has been a long-standing focus of interest. In this paper, we provide an overview of theoretical, modeling, laboratory, and field work on the role and relevance of ions for the formation of tropospheric aerosol particles, and on subsequent effects on clouds, and discuss briefly related research needs.
\end{abstract}

Keywords Troposphere $\cdot$ Aerosol nucleation $\cdot$ Ionization $\cdot$ Cosmic rays $\cdot$ Clouds

J. Kazil ( $\square)$

Max Planck Institute for Meteorology, Bundesstr. 53, 20146 Hamburg, Germany

e-mail: jan.kazil@zmaw.de

R.G. Harrison

Department of Meteorology, University of Reading, Earley Gate, PO Box 243, Reading, RG6 6BB, UK

e-mail: r.g.harrison@ reading.ac.uk

E.R. Lovejoy

NOAA Earth System Research Laboratory, Chemical Sciences Division, 325 Broadway, R/CSD2,

Boulder, CO 80305-3337, USA

e-mail: edward.r.lovejoy@noaa.gov 


\section{Introduction}

The continuous formation of charged particles in the atmosphere has been recognized since the late nineteenth century. These particles were identified as ions following studies on radioactivity and electrical conduction in gases (see Aplin et al. 2008). In early laboratory experiments, Wilson $(1897,1899)$ reported ion and particle formation in air and other gases in the presence of ultraviolet radiation and radioactive sources, and was the first to suggest that ions may be involved in atmospheric particle formation, and to realize the importance this could have for clouds (Galison 1997). Particle formation from the gas phase requires the emergence of molecular clusters of a size at which the condensation of further molecules is more likely than their evaporation, a process referred to as nucleation. Molecular clusters forming around ions are more stable compared to their neutral counterparts; ions can therefore trigger nucleation in conditions where neutral molecules would not. In the twentieth century, laboratory studies have confirmed Wilson's initial experiments (e.g. Bricard et al. 1968; Vohra et al. 1969; Raes and Janssens 1985), but research on atmospheric particle formation from ions has intensified only in the dawn of the twenty-first century with the heightened awareness of the relevance of new particle formation from the gas phase, which can significantly increase concentrations of aerosol particles and cloud condensation nuclei in the troposphere (Kulmala et al. 2004a), and thereby establishes a connection between atmospheric chemical composition, aerosols, clouds, and climate. Interest for the topic was also fueled by the possibility that the solar cycle modulation of atmospheric ionization through galactic cosmic rays could give rise to a similar modulation in aerosol and cloud droplet concentrations, and provide a mechanism to explain reported correlations between the decadal solar cycle and tropospheric observables, such as cloud cover (Svensmark and Friis-Christensen 1997; Marsh and Svensmark 2000; Carslaw et al. 2002; Harrison and Carslaw 2003).

\section{Tropospheric Aerosol}

Tropospheric aerosol particles are either emitted from the surface of the Earth, or form from the gas phase. Transport of aerosol particles from the stratosphere represents only a minor contribution to tropospheric aerosol. Major surface sources of aerosol particles include the oceans, which emit sea-salt particles, arid and semi-arid regions, where wind lifts mineral dust, and volcanoes, which inject particulate sulfate and ash into the atmosphere, while carbonaceous aerosols are produced by wildfires and by the combustion of fossil and biomass fuels. The formation of new aerosol particles from the gas phase requires sufficiently high concentrations of gas phase molecules with low saturation vapor pressure: for example, sulfuric acid which has a very low saturation vapor pressure in atmospheric conditions has been frequently reported as component of freshly formed aerosol, and appears to drive new particle formation in clean areas, such as over oceans (Clarke 1992; Brock et al. 1995). Over continents and, in particular, within the continental boundary layer, recently nucleated aerosol particles may contain, in addition to sulfate, substantial amounts of ammonia (Smith et al. 2005) or organic compounds (Allan et al. 2006; Cavalli et al. 2006), which may be involved in their formation process (Coffman and Hegg 1995; Marti et al. 1997a; Ball et al. 1999; O'Dowd et al. 2002; Kulmala et al. 2004b; Zhang et al. 2004; Burkholder et al. 2007). Freshly nucleated particles measure a few nanometers in diameter, much less than aerosol particles emitted from surface sources. In order to participate in atmospherically relevant processes, nucleated particles need to grow 
to sizes of tens of nanometers. Depending on the availability of condensable molecules, this process may proceed on time scales between minutes to days, and result finally in the formation of cloud condensation nuclei, particles which form cloud droplets. Kulmala et al. (2004a) found that nucleation from the gas phase may significantly increase concentrations of tropospheric cloud condensation nuclei. The resulting increase in cloud droplet concentrations may increase cloud albedo via the first (Twomey 1977) and cloud lifetime via the second indirect aerosol effect (Albrecht 1989). Pre-existing aerosol particles however quench the formation of new aerosol from the gas phase as they efficiently remove compounds which may initiate nucleation or contribute to particle growth, as well as the newly forming particles. The role played by gas phase particle formation in tropospheric processes therefore depends not only on the availability and distribution of nucleating and condensing compounds, but also on the presence, growth, transport, and removal of pre-existing particles. Similarly, the importance of charged nucleation in the troposphere depends not only on the availability of ions and molecules condensing on them, but also on the efficiency of competing neutral nucleation pathways.

\section{Ionization, Galactic Cosmic Rays, and Clouds}

Galactic cosmic rays (GCR) are a major source of ions in the troposphere (Bazilevskaya et al. 2008): upon entering the Earth atmosphere, primary cosmic ray particles, mostly hydrogen and helium nuclei, collide with atmospheric gas molecules and initiate a cascade of nuclear and electromagnetic reactions producing secondary cosmic rays. Due to the shape and orientation of the Earth's magnetic field, the GCR ionization rate increases from the magnetic equator towards the poles; its altitude profile has a peak in the upper troposphere/lower stratosphere. The GCR intensity and ionization rate are anti-correlated with the decadal solar cycle (Forbush 1954; Neher and Forbush 1958). A second important source of ionization in the troposphere is the radioactive decay of radon effusing from rocks and soils (Laakso et al. 2004b, and references therein). This source of ionization is strongest near the surface and in the boundary layer, and is not known to correlate with the solar cycle.

A mechanism linking galactic cosmic rays, aerosols and clouds was initially outlined by Dickinson (1975): sulfate aerosol particles forming from ions produced by GCR might grow to cloud condensation nuclei and eventually become cloud droplets. The variation of GCR ionization over the solar cycle would thus appear in cloud droplet concentrations and hence in cloud albedo via the first (Twomey 1977) and cloud lifetime via the second (Albrecht 1989 ) indirect aerosol effect. The result would be a solar cycle modulation of radiative forcing of the troposphere. A corresponding correlation was first reported by Svensmark and Friis-Christensen (1997), who found a 3-4\% variation of the global cloud cover over a solar cycle based on data of the International Satellite Cloud Climatology Project (ISCCP) (Rossow and Schiffer 1991) for the years 1983-1992. Kristjánsson and Kristiansen (2000) pointed out that the correlation may be purely coincidental, as the ISCCP data showed a divergence of cloud cover and GCR intensity in the years 1991-1994, but concluded that global cloud fraction is higher by 0.0176 and radiative forcing reduced by $0.29 \mathrm{~W} \mathrm{~m}^{-2}$ at solar minimum 1986 compared with solar maximum 1990. Marsh and Svensmark (2000) confined the correlation to low clouds for the period 1983-1994. They estimated that global low cloud fraction is higher at solar minimum by 0.02 and radiative forcing reduced by $1.2 \mathrm{~W} \mathrm{~m}^{-2}$ compared with solar maximum. Kristjánsson et al. $(2002,2004)$ analyzed the revised ISCCP cloud dataset (Rossow and Schiffer 1999) for the period 1983-2001 and found a weak correlation between low cloud cover and GCR intensity. Harrison and Stephenson 
(2006) found a small yet statistically significant effect of cosmic rays on daily regional cloudiness, based on surface radiation measurements. In a recent statistical analysis of the ISCCP data, Sloan and Wolfendale (2008) found only very limited support for a connection between the decadal variation in galactic cosmic ray ionization and low cloud cover.

\section{Field Observations of New Particle Formation and Ions}

Evidence for the involvement of ions in the nucleation of tropospheric aerosol particles includes observations of bursts of intermediate size ions followed by increases in ultrafine aerosol in the boundary layer (Hõrrak et al. 1998), and direct observation of very large cluster ions in the upper troposphere (Eichkorn et al. 2002). Charged nucleation in the upper troposphere is also supported by the observations of Lee et al. (2003), who used results obtained with the laboratory data based model of Lovejoy et al. (2004) to explain the measured high ultrafine aerosol concentrations. Laakso et al. (2004a) and Laakso et al. (2007a) observed nucleation events in the boundary layer over the boreal forest and identified events when charged nucleation was contributing to particle formation by preferential growth of negatively charged clusters. However, during a large fraction of these events, neutral nucleation dominated particle formation, with a marginal contribution from charged nucleation. Similarly, Vana et al. (2006) identified negative molecular clusters as preferred condensation centers in particle formation events observed over the boreal forest. The contribution of charged nucleation appeared highest for comparatively weak particle formation events, while during strong particle formation events, the contribution of charged nucleation was reduced. Eisele et al. (2006) measured size and mobility distributions of charged molecular clusters and aerosol particles at a continental site, and found that while ions contributed to the formation of small charged sulfate clusters, charged nucleation did not play a significant role in aerosol production during these measurements. Laakso et al. (2007b) conducted a study of boundary layer ion and aerosol profiles over the boreal forest with a hot air balloon. These measurements showed a distinct asymmetry between the negative and positive aerosol size distribution, with concentrations of nanometer-sized negative particles exceeding those of corresponding positive particles throughout the mixed layer. This indicates charged nucleation in which negative ions played a significant role; however, neutral nucleation was found to contribute to the observed particle nucleation events as well. Calculations using the method of Kazil and Lovejoy (2007) showed that charged nucleation of sulfuric acid and water was not able to explain the observations alone, indicating a compound other than sulfuric acid stabilizing the negative clusters. Laakso et al. (2007b) proposed that this stabilizing component is an organic molecule.

The contribution of neutral nucleation to the particle formation events reported in the above studies may be driven by organic molecules (O'Dowd et al. 2002) or ammonia (Coffman and Hegg 1995), which are supported as nucleation agents by laboratory studies (Marti et al. 1997a; Ball et al. 1999; Zhang et al. 2004; Kulmala et al. 2006; Burkholder et al. 2007). On the other hand, several field campaigns at forested sites have found no indication for organic molecules participating in boundary layer aerosol nucleation: Marti et al. (1997b) and Sellegri et al. (2005) concluded the organic compounds play a role for condensational growth of aerosol particles, rather than in their nucleation. Similarly, Janson et al. (2001) found that organic molecules were not the nucleating species responsible for nucleation events in the boundary layer, but sulfuric acid and ammonia, while subsequent particle growth ought to have been due to condensation of organic compounds. A role of ammonia in aerosol nucleation is contended as well, as is discussed in the next section. 


\section{Laboratory Measurements}

There has been a significant experimental effort aimed at understanding possible atmospheric nucleation mechanisms (see e.g. reviews by Laaksonen et al. 1995; Curtius 2006; O'Dowd and Wagner 2008). Here we focus our discussion on recent experimental work, and emphasize sulfuric acid-based schemes. Neutral nucleation of sulfuric acid and water has long been regarded as an important source of new particles in the atmosphere, largely due to in situ atmospheric $\mathrm{H}_{2} \mathrm{SO}_{4}$ production, extremely low $\mathrm{H}_{2} \mathrm{SO}_{4}$ vapor pressure in the presence of water, and optimistic predictions from classical nucleation theory (discussed in Sect. 6). In a seminal work, Wyslouzil et al. (1991) measured the nucleation rates of $\mathrm{H}_{2} \mathrm{SO}_{4}$ and $\mathrm{H}_{2} \mathrm{O}$ as function of temperature, relative humidity, and $\mathrm{H}_{2} \mathrm{SO}_{4}$ concentration, and found a strong dependence on these variables. Ball et al. (1999) reported the nucleation rate as a function of the concentration of sulfuric acid for a range of relative humidities. A major achievement of this work was the direct measurement of sulfuric acid concentration within the nucleation reactor. Both experiments yielded nucleation rates that were significantly lower than predictions of classical nucleation theory.

Laboratory studies of atmospheric gas phase $\mathrm{H}_{2} \mathrm{SO}_{4}$ nucleation have advanced to study the individual elementary clustering reactions in recent years. The goal of these studies is to measure the thermochemical parameters (enthalpy and entropy change) of the step-wise cluster formation reactions, and use these data to develop kinetic models that accurately predict nucleation rates as a function of atmospheric conditions. Such experiments give valuable new insight into the elementary steps involved in particle formation, but are a significant undertaking for even simple binary systems because of the large number of reactions that need to be evaluated to accurately describe the kinetics of the system. However, accurate thermochemical parameters for even the initial few clustering reactions are extremely useful, and can strongly constrain nucleation rates. Clustering of the charged sulfuric acid water system has received considerable experimental attention, because of the expected atmospheric relevance of sulfuric acid in new particle formation, and because ions are directly observable with mass spectrometry. Eisele and Hanson (2000) were the first to observe and resolve on the molecular scale the nucleation of charged sulfuric acid clusters from precursor ions. Curtius et al. (2001) and Lovejoy and Curtius (2001) measured the thermochemical parameters for sulfuric acid uptake and Froyd and Lovejoy (2003a, 2003b) the thermochemical parameters for water uptake by small neutral and charged sulfuric acid clusters. These experimental data constitute a matrix of thermochemical parameters describing charged nucleation of sulfuric acid and water. Similar experiments were conducted by Wilhelm et al. (2004) and Sorokin et al. (2006). These ion clustering thermochemical studies show that sulfuric acid has a stronger affinity for the hydrated negative ions than the positive ions, and hence the positive ions are less likely to grow in typical tropospheric conditions.

Hanson and Lovejoy (2006) measured the thermochemical parameters for the formation of the neutral hydrated dimer and trimer of sulfuric acid, averaged over the water contents of the particles. These thermochemical data strongly constrain the atmospheric relevance of this process, and show that classical nucleation theory overestimates the stability of the small neutral sulfuric acid/water clusters and the corresponding nucleation rates, consistent with the results of Wyslouzil et al. (1991) and Ball et al. (1999). While these results indicate that the neutral nucleation of $\mathrm{H}_{2} \mathrm{SO}_{4}$ and $\mathrm{H}_{2} \mathrm{O}$ is inefficient in the lower troposphere, Hanson and Lovejoy (2006) show that this mechanism is potentially important in the cold upper troposphere, where it is likely to overwhelm the corresponding charged process.

Berndt et al. (2005) observed new particle formation in the sulfuric acid-water system at $\mathrm{H}_{2} \mathrm{SO}_{4}$ concentrations exceeding $10^{10} \mathrm{~cm}^{-3}$, generated by evaporation from a liquid sample, 
similar to concentrations reported by Wyslouzil et al. (1991) and Ball et al. (1999). However, when the sulfuric acid was generated in the gas phase photochemically, Berndt et al. (2005) found that much lower $\mathrm{H}_{2} \mathrm{SO}_{4}$ concentrations, around $10^{7} \mathrm{~cm}^{-3}$, such as occurring in the atmosphere, were sufficient to initiate new particle formation. A possible explanation for the low threshold sulfuric acid concentrations and high particle formation rates when using photochemically produced sulfuric acid may be organic molecules used by Berndt et al. (2005) to determine the concentrations of gas phase $\mathrm{OH}$ and $\mathrm{H}_{2} \mathrm{SO}_{4}$, which may have contributed to the formation of new particles. In a subsequent study, however, Berndt et al. (2006) investigated nucleation of $\mathrm{H}_{2} \mathrm{SO}_{4}$ and $\mathrm{H}_{2} \mathrm{O}$ in the absence of organic compounds, and with $\mathrm{H}_{2} \mathrm{SO}_{4}$ forming in the gas phase with or without UV photochemistry. In this study, particle formation commenced at sulfuric acid concentrations around $10^{7} \mathrm{~cm}^{-3}$, indicating no significant role of the organic compounds used in the Berndt et al. (2005) work. At the same time, no significant differences between the experiments with $\mathrm{H}_{2} \mathrm{SO}_{4}$ produced in the gas phase with or without UV photochemistry were found, ruling against a possible contribution of charged nucleation due to UV-produced ions in the experiment. Neutral nucleation of sulfuric acid and water proceeding at the low concentrations of gas phase sulfuric acid observed by Berndt et al. (2005) and Berndt et al. (2006) would significantly abate a role of charged nucleation of these compounds in the troposphere.

While the results of Berndt et al. (2006) indicate that the organic compounds used do not promote the formation of $\mathrm{H}_{2} \mathrm{SO}_{4} / \mathrm{H}_{2} \mathrm{O}$ particles from the gas phase, other organic compounds may trigger or support nucleation of sulfate aerosol: Zhang et al. (2004) have observed enhanced formation of neutral sulfuric acid particles from the gas phase in the presence of aromatic organic acids in the laboratory. Based on theoretical work, they postulate that a strong aromatic acid- $\mathrm{H}_{2} \mathrm{SO}_{4}$ interaction facilitates nucleation.

The role of ammonia for sufate aerosol formation has not been conclusively established yet: Kim et al. (1998) investigated particle formation from a $\mathrm{NH}_{3} / \mathrm{SO}_{2} / \mathrm{H}_{2} \mathrm{O} /$ air mixture in the presence of ionizing radiation, and observed enhanced particle concentrations in the presence of $\mathrm{NH}_{3}$, although the enhancement depended greatly on the $\mathrm{SO}_{2}, \mathrm{NH}_{3}$ and $\mathrm{H}_{2} \mathrm{O}$ concentrations. Particle formation was also found to proceed faster in the $\mathrm{NH}_{3} / \mathrm{SO}_{2} / \mathrm{H}_{2} \mathrm{O}$ /air mixture, with a lower contribution of charged nucleation compared to the $\mathrm{SO}_{2} / \mathrm{H}_{2} \mathrm{O} /$ air mixture. However, charged nucleation was identified as a main mechanism at an early stage of particle generation in both mixtures. Ball et al. (1999) have shown a significant enhancement in the nucleation rate of the neutral $\mathrm{NH}_{3} / \mathrm{SO}_{2} / \mathrm{H}_{2} \mathrm{O}$ system relative to the neutral $\mathrm{H}_{2} \mathrm{SO}_{4} / \mathrm{H}_{2} \mathrm{O}$ system, while Anttila et al. (2005), Yu (2006b), and Kurtén et al. (2007) have found that ammonia may not be an effective nucleation agent. Laboratory measurements of the thermochemical parameters for selected steps of charged $\mathrm{H}_{2} \mathrm{SO}_{4} / \mathrm{NH}_{3} / \mathrm{H}_{2} \mathrm{O}$ nucleation have been conducted by Froyd (2002).

\section{Theory}

Classically, the nucleation of neutral particles from the gas phase is described with the Kelvin-Thomson equation (Thomson 1906), which gives the Gibbs free energy $\Delta G_{n}$ released in the uptake of a gas phase molecule by a neutral, spherical liquid droplet:

$$
\Delta G_{n}=-\frac{4}{3} \pi R^{3} \frac{k T}{v} \ln S+4 \pi R^{2} \sigma
$$

with the droplet radius $R$, its surface tension $\sigma$, and the supersaturation ratio $S$ of the nucleating compound above a flat liquid surface with the composition of the droplet (see e.g. 
Curtius 2006 and references therein). $T$ is the temperature of the system, $k$ the Boltzmann constant, and $v$ the volume of the nucleating molecules. Note that adding a molecule is endothermic for radii smaller than a critical radius $R^{*}$, and exothermic for larger radii. The critical radius $R^{*}$ and the Gibbs energy $\Delta G_{n}^{*}$ required to form a critical droplet can be determined by solving $\frac{\partial \Delta G_{n}}{\partial R} \doteq 0$. The classical nucleation rate in steady state may then be written (Volmer and Weber 1926) as

$$
J=C \exp \left(-\frac{\Delta G_{n}^{*}}{k T}\right) .
$$

The factor $C$ accommodates concentrations of condensable molecules and their reaction coefficients, and has been discussed by Farkas (1927) and Becker and Döring (1935) for a unary and by Reiss (1950) for a binary system. If the droplet is charged, then the uptake of a molecule from the gas phase changes the electric field energy of the charged droplet due to the increase in the volume occupied by a dielectric liquid. Thus for a charge that resides at the center of the droplet, the Gibbs free energy released by the uptake of a molecule is (in SI units)

$$
\Delta G_{c}=\Delta G_{n}-\frac{q^{2}}{8 \pi}\left(\frac{1}{\epsilon_{0}}-\frac{1}{\epsilon_{1}}\right)\left(\frac{1}{R}-\frac{1}{R+\Delta R}\right) .
$$

$\epsilon_{0}$ and $\epsilon_{1}$ are the permittivities of the gas and liquid phase, $R$ and $R+\Delta R$ the radii of the liquid droplet before and after the uptake of the molecule, respectively. Commonly, $\epsilon_{1}>\epsilon_{0}>1$ and $R+\Delta R>R>0$, hence $\Delta G_{c}<\Delta G_{n}$, meaning that the charged droplet is more stable than the neutral droplet. Based on this formulation of classical nucleation theory, Yue and Chan (1979) investigated the formation of aerosols through the nucleation of a binary mixture of vapors and in the presence of ion sources, and derived analytical expressions for estimating the composition, radius $R^{*}$, and Gibbs energy of formation $\Delta G_{c}^{*}$ of critical droplets formed through the charged nucleation process.

$\mathrm{Yu}$ (2005) extended charged classical nucleation theory by accounting for the interaction between the droplet charge and the dipole moment of the condensing gas phase molecules. The charge-dipole interaction further reduces the Gibbs free energy for the uptake of gas phase molecules molecule and increases the stability of the charged droplet. Accounting for the charge-dipole interaction in the calculation of the entropies and enthalpies for the uptake of molecules by small charged molecular clusters improves the agreement with observations (Yu 2005).

However, the concept of a liquid droplet characterized by a bulk solution and a composition-dependent surface tension breaks down in the context of very small particles (diameters $\sim 1 \mathrm{~nm}$ and less). Such small particles are better described as molecular clusters: in these, molecules arrange in a different spatial structure compared to molecules in a bulk liquid, resulting in different thermochemical parameters for the uptake and loss of gas phase molecules. As a consequence, classical nucleation theory overestimates the stability of very small particles and nucleation rates; in the case of neutral $\mathrm{H}_{2} \mathrm{SO}_{4} / \mathrm{H}_{2} \mathrm{O}$ clusters, classical steady state nucleation rates are significantly higher than nucleation rates inferred in laboratory measurements (Wyslouzil et al. 1991; Ball et al. 1999; Hanson and Lovejoy 2006). In addition, the structure of the molecular clusters and of the gas phase molecules (Nadykto et al. 2004), as well as the shape of their interaction potential (Langevin 1905; Chesnavich et al. 1980; Nadykto and Yu 2003) affect their collision rate coefficients. Finally, the assumptions of steady state, and of a negligible role of self-coagulation and coagulation with pre-existing aerosol in the formation of supercritical clusters used in classical nucleation theory need not be valid in all conditions. For these reasons, more sophisticated 
approaches to aerosol nucleation, which account for the individual cluster-molecule reactions, the structure of the molecules and molecular clusters, and the interaction of subcritical and supercritical particles, have been developed. These approaches are typically not accessible by analytical methods but require numerical modeling, discussed in the next section.

\section{Modeling}

The most straightforward step beyond classical nucleation theory is the kinetic modeling of particle formation, i.e. as a process of repeated uptake (and loss) of gas phase molecules, with the reaction of two gas phase molecules forming a dimer as the initial step. The thermochemical parameters from the liquid drop model can be used to describe the individual steps, with the same limitations as discussed in the preceding section, except that here steady-state is not assumed, and self-coagulation of the subcritical particles, and their coagulation with pre-existing aerosol are accounted for. At the next level, the structure of the molecular clusters and gas phase molecules involved can be represented implicitly by using thermochemical parameters for the uptake and loss of the molecules from the gas phase by the clusters obtained from extensions of the liquid drop approach, ab initio calculations, or from laboratory measurements. The thermochemical parameters and the corresponding forward and reverse rate coefficients can be calculated based on different assumptions and treatments of the cluster-molecule interaction potential (Langevin 1905; Chesnavich et al. 1980; Su and Chesnavich 1982; Nadykto and Yu 2003; Lovejoy et al. 2004; Yu 2005; Yu 2007). The most widely investigated aerosol nucleation pathway via the clustering of sulfuric acid and water is commonly reduced to a system where only the uptake of sulfuric acid is resolved in individual steps, and uptake and loss of water is described in steady state. This treatment is considered valid in tropospheric conditions, where water vapor concentrations exceed the concentration of sulfuric acid by orders of magnitude, hence allowing sulfuric acid/water clusters to equilibrate with respect to water uptake and loss between individual sulfuric acid uptake/loss events.

In an early combined modeling/experimental study, Raes and Janssens $(1985,1986)$ investigated neutral and charged nucleation in a mixture of gaseous sulfuric acid and water, using a model of classical neutral and charged nucleation. They observed an increase in particle concentration upon exposure of the mixture to $\gamma$ radiation, indicating the occurrence of charged nucleation, which could, however, be reproduced only in part in their simulations. Using the same model, Raes et al. (1986) investigated aerosol formation over oceans, and concluded that charged nucleation may be the only source of new aerosol particles forming from the gas phase over the oceans.

Turco et al. (1998) proposed and investigated, using their model of sulfuric acid/water aerosol, the recombination of oppositely charged molecular clusters as the process maintaining tropospheric background aerosol concentrations: this mechanism could produce supercritical aerosol particles in conditions which do not support the formation of such particles by charged (negative or positive) nucleation. Yu and Turco (2000) were able to explain observed ion mobility spectra as well as nucleation events and ultrafine particle concentrations at different sites with charged aerosol nucleation. In as subsequent study, Yu and Turco (2001) found that variations in ionization, e.g. from the modulation of GCR intensity by the solar cycle, are capable of causing a significant variation in aerosol production. Yu (2002) modeled the response of aerosol production to variations in GCR intensity during a solar cycle as a function of altitude. The results show a positive correlation of aerosol production and GCR intensity in the lower troposphere and a negative correlation in the upper 
troposphere. In the middle troposphere, the aerosol production was insensitive to changes in the ionization. These findings are consistent with the GCR-cloud correlation of Marsh and Svensmark (2000), apparent for low tropospheric clouds.

Laakso et al. (2002) developed a model of neutral, negative, and positive $\mathrm{H}_{2} \mathrm{SO}_{4} / \mathrm{H}_{2} \mathrm{O}$ aerosol which accounts, above a certain size, for multiply charged particles. One interesting result of this work is that final particle concentrations are very similar independent of whether both negative and positive particles (symmetric case) nucleate and grow, or only negative particles (asymmetric case). In the asymmetric case, however, the size distributions of positive and negative particles differ during nucleation, a fact which may be exploited experimentally to identify the nucleation pathway. Kerminen et al. (2007) investigated this idea in detail and developed an approach for the assessment of the contribution of neutral and charged nucleation to a particle formation event.

The modeling approaches discussed so far employed thermochemical parameters for the formation of neutral and charged molecular clusters that were derived from classical nucleation theory. Lovejoy et al. (2004) developed a detailed aerosol model of neutral and negative $\mathrm{H}_{2} \mathrm{SO}_{4} / \mathrm{H}_{2} \mathrm{O}$ aerosol particles. Small neutral and negative $\mathrm{H}_{2} \mathrm{SO}_{4} / \mathrm{H}_{2} \mathrm{O}$ clusters are resolved individually, and larger particles with geometric bins. Laboratory thermochemical parameters measured by Curtius et al. (2001) and Froyd and Lovejoy (2003b) for the small negative $\mathrm{H}_{2} \mathrm{SO}_{4} / \mathrm{H}_{2} \mathrm{O}$ clusters were used. Thermochemical parameters for small neutral $\mathrm{H}_{2} \mathrm{SO}_{4} / \mathrm{H}_{2} \mathrm{O}$ clusters were obtained from the liquid drop model, adjusted to reproduce the laboratory measurements of Ball et al. (1999). Positive particles were represented summarily by a positive molecular cluster of a given mass. The thermodynamic data for large aerosol particles were derived from $\mathrm{H}_{2} \mathrm{SO}_{4}$ and $\mathrm{H}_{2} \mathrm{O}$ vapor pressures over bulk solutions, and from the liquid drop model. Thermodynamic data for intermediate size particles were obtained by smoothly interpolating the data for the small and large particles. The model predicts that charged nucleation of $\mathrm{H}_{2} \mathrm{SO}_{4}$ and $\mathrm{H}_{2} \mathrm{O}$ proceeds efficiently in the middle and upper troposphere, and explained nucleation events observed in the remote middle troposphere with the charged $\mathrm{H}_{2} \mathrm{SO}_{4} / \mathrm{H}_{2} \mathrm{O}$ mechanism, but not generally nucleation events observed in the boundary layer (Lovejoy et al. 2004). The model also correctly reproduced measurements of subcritical charged $\mathrm{H}_{2} \mathrm{SO}_{4} / \mathrm{H}_{2} \mathrm{O}$ clusters and the simultaneous absence of their growth to larger sizes in the boundary layer at a continental site (Eisele et al. 2006), confirming that charged nucleation of these compounds was not responsible for the observed particle formation events.

Kazil and Lovejoy (2004) applied the Lovejoy et al. (2004) model to the conditions studied by Yu (2002) and investigated the response of aerosol formation to changes in the ionization rate, such as resulting from the modulation of the GCR intensity by the decadal solar cycle. They obtained a positive correlation of aerosol formation and ionization throughout the troposphere in the adopted conditions. Still, depending on conditions, either a negative or a positive correlation of the nucleation and ionization rates was shown to be possible, which was explained as follows: an increase in the ionization rate enhances nucleation when growth of subcritical charged clusters exceeds their loss by recombination, and reduces nucleation in the opposite case.

$\mathrm{Yu}$ (2007) developed a detailed model of positive, negative, and neutral $\mathrm{H}_{2} \mathrm{SO}_{4} / \mathrm{H}_{2} \mathrm{O}$ aerosol particles, forming by neutral and charged nucleation of sulfuric acid and water, and growing by uptake of these compounds as well as by condensation of organic molecules. The role of the charge for the composition of small $\mathrm{H}_{2} \mathrm{SO}_{4} / \mathrm{H}_{2} \mathrm{O}$ clusters is accounted for in detail. The model resolves the small $\mathrm{H}_{2} \mathrm{SO}_{4} / \mathrm{H}_{2} \mathrm{O}$ clusters individually, and larger particles with geometric bins. The thermochemical parameters for the uptake/loss of sulfuric acid are implemented via the evaporation rate coefficients: For the neutral $\mathrm{H}_{2} \mathrm{SO}_{4} / \mathrm{H}_{2} \mathrm{O}$ clusters, $\mathrm{H}_{2} \mathrm{SO}_{4}$ evaporation rate coefficients are calculated after $\mathrm{Yu}(2006 \mathrm{a})$; for the positive and 
negative clusters, the effect of the charge and of the charge-dipole interaction (Yu 2005) on the evaporation rate coefficients are accounted for. The model predicts that charged nucleation can lead to significant new particle formation in the lower atmosphere due to charged nucleation of sulfuric acid and water, supporting a more general role of ions in aerosol nucleation in the boundary layer than indicated by the simulations of Lovejoy et al. (2004). This vigorous particle formation can be possibly traced to the size-resolved treatment of positive clusters in the model, which could extend negative cluster lifetimes, or to the adopted thermochemical parameters.

Kazil et al. (2006) operated the Lovejoy et al. (2004) model on long term average ambient conditions and composition data in the troposphere over the oceans, obtained from reanalysis and chemical transport model runs. These simulations predict negligible charged and neutral nucleation of $\mathrm{H}_{2} \mathrm{SO}_{4}$ and $\mathrm{H}_{2} \mathrm{O}$ in the tropical lower troposphere, even in the absence of pre-existing aerosol. At mid-latitudes, charged nucleation would proceed efficiently, provided that pre-existing aerosol particles are depleted e.g. by precipitation, and exceed neutral nucleation. The simulations also show very efficient charged nucleation in the tropical upper troposphere up to the highest considered model level. At higher altitudes, however, neutral nucleation is likely to dominate (Hanson and Lovejoy 2006). Using correlations between aerosol concentrations and cloud properties derived from satellite observations, Kazil et al. (2006) estimated that the difference in daily mean shortwave radiative forcing between solar maximum and minimum due to the response of cloud cover and albedo to the difference in charged aerosol nucleation in the lower troposphere falls short of the difference of absorbed solar irradiance between solar maximum and minimum of $0.24 \mathrm{~W} \mathrm{~m}^{-2}$ due to the concurrent variation in solar radiative output. This upper limit estimate is much smaller than the difference in radiative forcing of $1.2 \mathrm{~W} \mathrm{~m}^{-2}$ between solar maximum and minimum given by Marsh and Svensmark (2000) due to the variation of low cloud cover based on ISCCP data (Rossow and Schiffer 1999) for the period 1983-1994, but close to the value of Kristjánsson and Kristiansen (2000), who found, based on the same cloud data, that radiative forcing was reduced by $0.29 \mathrm{~W} \mathrm{~m}^{-2}$ at solar minimum 1986 compared with solar maximum 1990 .

Most recently, Yu et al. (2008) conducted a global study of charged nucleation of $\mathrm{H}_{2} \mathrm{SO}_{4}$ and $\mathrm{H}_{2} \mathrm{O}$ in a chemical transport model, using nucleation rates calculated with the model of $\mathrm{Yu}$ (2007). The resulting nucleation rates compare favorably with a comprehensive dataset of new aerosol formation events, showing agreement in the spatial distribution and strength in aerosol nucleation: At mid-latitudes, in the northern hemisphere, and in particular over continents, lower tropospheric nucleation rates are significantly stronger compared with tropical latitudes, the southern hemisphere, and oceans, respectively. Charged nucleation is also shown to proceed very efficiently in the tropical upper troposphere. A comparison of the simulated nucleation rates with primary particle emissions rates positions charged nucleation as a significant source of aerosol on a global scale, possibly explaining many observed new particle formation events.

\section{Summary and Outlook}

Groundbreaking studies have cleared some of the fog blurring our understanding of particle formation from the gas phase in the atmosphere and the role of ions therein: Laboratory studies have identified neutral and charged nucleation of sulfuric acid and water as efficient processes for new particle formation from the gas phase in favorable conditions, placed corresponding model simulations on a dependable footing, and helped understanding the relative importance of these processes in the atmosphere. Neutral nucleation of sulfuric acid 
and water appears more efficient than charged nucleation of these compounds in the cold upper troposphere, although charged nucleation has been found to proceed in this atmospheric region as well. In the middle and lower troposphere, neutral nucleation of sulfuric acid and water is likely to be negligible. Field observations indicate that while both neutral and charged nucleation proceed in these regions, in the continental boundary layer, where most field studies have been performed, neutral nucleation is more frequent and efficient, and involves chemical compounds beyond sulfuric acid and water. On the other hand, charged nucleation of sulfuric acid and water has been found to explain the observed nucleation events in modeling studies, depending on the implementation of the nucleation process and the thermochemical data used. However, models agree that variations in ionization such as occurring in the course of the decadal solar cycle have a considerable effect on the charged nucleation rate, although no uncontested effect on concentrations of cloud condensation nuclei or on clouds themselves has been found. Possible explanations are that charged nucleation may also arise from ionization due to decay of radon, which does not vary with the solar cycle, and has to compete with neutral nucleation mechanisms and surface aerosol emissions.

In order to quantify the contribution of ions to atmospheric aerosol nucleation and identify the conditions in which charged nucleation matters as well as their spatial distribution, both charged and neutral nucleation processes need to be understood. Conflicting research results complicate the task: The species involved in neutral nucleation in addition to sulfuric acid are thought to be organic molecules and ammonia, but theoretical, field, and laboratory studies have come to contrasting findings on the role of these compounds. An additional complication arises from the possibility that these compounds may be involved in charged nucleation as well. The questions surrounding the relevance of ions for atmospheric nucleation are therefore far from settled, and numerous research challenges await their solution: Methods for the determination of the composition of small clusters observed in the atmosphere need to be improved and corresponding field studies conducted to identify the compounds involved in aerosol nucleation. Laboratory and ab initio studies on the structure and thermochemical parameters for the formation of small neutral and charged molecular clusters, in particular those containing sulfuric acid, ammonia, and water, as well as organic molecules, are needed to understand the relative contributions of neutral and charged nucleation to new particle formation, and to improve the representation of aerosol nucleation in atmospheric models. Such representations will have to be able to simultaneously accommodate different nucleation pathways. They must be computationally efficient on the one hand, but reproduce results obtained with a detailed model with sufficient precision on the other. At the same time, the sensitivity of processes in atmospheric models to aerosol nucleation needs to be investigated: Aerosol nucleation competes against aerosol emissions from the surface, and changes in the nucleation rate need not to translate into similar changes in aerosol and cloud condensation nuclei concentrations, or cloud properties. However, a limited sensitivity of atmospheric models to nucleation rates changes needs not necessarily imply an insensitivity of the actual atmosphere to aerosol nucleation or to changes thereof. These steps will bring us closer to understanding aerosol nucleation in the atmosphere and the contribution of ions, as well as the possible links between solar variability and the troposphere.

Acknowledgements We thank D. O’Donnell (Max Planck Institute for Meteorology) for helpful comments, and two anonymous referees for their thoughtful review of this manuscript. 


\section{References}

B.A. Albrecht, Aerosols, cloud microphysics and fractional cloudiness. Science 245, 1227-1230 (1989)

J.D. Allan, M.R. Alfarra, K.N. Bower, H. Coe, J.T. Jayne, D.R. Worsnop, P.P. Aalto, M. Kulmala, T. Hyötyläinen, F. Cavalli, A. Laaksonen, Size and composition measurements of background aerosol and new particle growth in a Finnish forest during QUEST 2 using an Aerodyne Aerosol Mass Spectrometer. Atmos. Chem. Phys. 6, 315-327 (2006)

T. Anttila, H. Vehkamäki, I. Napari, M. Kulmala, Effect of ammonium bisulphate formation on atmospheric water-sulphuric acidammonia nucleation. Boreal Environ. Res. 10, 511-523 (2005)

K.L. Aplin, R.G. Harrison, M.J. Rycroft, Investigation of Earth's atmospheric electricity: a role model for planetary studies, Space Sci. Rev. (2008, this issue)

S.M. Ball, D.R. Hanson, F.L. Eisele, P.H. McMurry, Laboratory studies of particle nucleation: Initial results for $\mathrm{H}_{2} \mathrm{SO}_{4}, \mathrm{H}_{2} \mathrm{O}$, and $\mathrm{NH}_{3}$ vapors. J. Geophys. Res. 104, 23 709-23 718 (1999)

G.A. Bazilevskaya, I.G. Usoskin, E. Flückiger, R.G. Harrison, L. Desorgher, R. Bütikofer, M.B. Krainev, V.S. Makhmutov, Y.I. Stozhkov, A.K. Svirzhevskaya, N.S. Svirzhevsky, G.A. Kovaltsov, Cosmic ray induced ion production in the atmosphere. Space Sci. Rev. (2008, this issue) doi:10.1007/s11214-0089339-y

R. Becker, W. Döring, Kinetische Behandlung der Keimbildung in übersättigten Dämpfen. Ann. d. Phys. 416, 719-752 (1935)

T. Berndt, O. Böge, F. Stratmann, J. Heintzenberg, M. Kulmala, Rapid formation of sulfuric acid particles at near-atmospheric conditions. Science 307, 698-700 (2005)

T. Berndt, O. Böge, F. Stratmann, Formation of atmospheric $\mathrm{H}_{2} \mathrm{SO}_{4} / \mathrm{H}_{2} \mathrm{O}$ particles in the absence of organics: A laboratory study. Geophys. Res. Lett. 33, L15817 (2006)

J. Bricard, F. Billard, G. Madelaine, Formation and evolution of nuclei of condensation that appear in air initially free of aerosols. J. Geophys. Res. 73, 4487-4496 (1968)

C.A. Brock, P. Hamill, J.C. Wilson, H.H. Jonsson, K.R. Chan, Particle formation in the upper tropical troposphere: a source of nuclei for the stratospheric aerosol. Science 270, 1650-1653 (1995)

J.B. Burkholder, T. Baynard, A.R. Ravishankara, E.R. Lovejoy, Particle nucleation following the $\mathrm{O}_{3}$ and $\mathrm{OH}$ initiated oxidation of $\alpha$-pinene and $\beta$-pinene between 278 and 320 K. J. Geophys. Res. 112, 10216 (2007)

K.S. Carslaw, R.G. Harrison, J. Kirkby, Cosmic rays, clouds, and climate. Science 298, 1732-1737 (2002)

F. Cavalli, M.C. Facchini, S. Decesari, L. Emblico, M. Mircea, N.R. Jensen, S. Fuzzi, Size-segregated aerosol chemical composition at a boreal site in southern Finland, during the QUEST project. Atmos. Chem. Phys. 6, 993-1002 (2006)

W.J. Chesnavich, T. Su, M.T. Bowers, Collisions in a noncentral field: A variational and trajectory investigation of ion-dipole capture. J. Chem. Phys. 72, 2641-2655 (1980)

A.D. Clarke, Atmospheric nuclei in the remote free-troposphere. J. Atmos. Chem. 14, 479-488 (1992)

D.J. Coffman, D.A. Hegg, A preliminary study of the effect of ammonia on particle nucleation in the marine boundary layer. J. Geophys. Res. 100, 7147-7160 (1995)

J. Curtius, Nucleation of atmospheric aerosol particles. C.R. Phys. 7, 1027-1045 (2006)

J. Curtius, K.D. Froyd, E.R. Lovejoy, Cluster ion thermal decomposition (I): Experimental kinetics study and $\mathrm{ab}$ initio calculations for $\mathrm{HSO}_{4}^{-}\left(\mathrm{H}_{2} \mathrm{SO}_{4}\right)_{(x)}\left(\mathrm{HNO}_{3}\right)_{(y)}$. J. Phys. Chem. A 105, 10867-10873 (2001)

R.E. Dickinson, Solar variability and the lower atmosphere. Bull. Am. Meteorol. Soc. 56, 1240-1248 (1975)

S. Eichkorn, S. Wilhelm, H. Aufmhoff, K.H. Wohlfrom, F. Arnold, Cosmic ray-induced aerosol-formation: First observational evidence from aircraft-based ion mass spectrometer measurements in the upper troposphere. Geophys. Res. Lett. 29 (2002)

F.L. Eisele, D.R. Hanson, First measurement of prenucleation molecular clusters. J. Phys. Chem. A 104, 830-836 (2000)

F.L. Eisele, E.R. Lovejoy, E. Kosciuch, K.F. Moore, R.L. Mauldin III, J.-N. Smith, P.H. McMurry, K. Iida, Negative atmospheric ions and their potential role in ion-induced nucleation. J. Geophys. Res. 111, D043053 (2006)

L. Farkas, Keimbildungsgeschwindigkeit in übersättigten Dämpfen. Z. Phys. Chem. 125, 236-242 (1927)

S.E. Forbush, Worldwide cosmic ray variations, 1937-1952. J. Geophys. Res. 59, 525-542 (1954)

K.D. Froyd, Ion induced nucleation in the atmosphere: Studies of $\mathrm{NH}_{3}, \mathrm{H}_{2} \mathrm{SO}_{4}$, and $\mathrm{H}_{2} \mathrm{O}$ cluster ions. $\mathrm{Ph} . \mathrm{D}$. thesis, University of Colorado at Boulder, 2002

K.D. Froyd, E.R. Lovejoy, Experimental thermodynamics of cluster ions composed of $\mathrm{H}_{2} \mathrm{SO}_{4}$ and $\mathrm{H}_{2} \mathrm{O}$. 1. Positive Ions. J. Phys. Chem. A 107, 9800-9811 (2003a)

K.D. Froyd, E.R. Lovejoy, Experimental thermodynamics of cluster ions composed of $\mathrm{H}_{2} \mathrm{SO}_{4}$ and $\mathrm{H}_{2} \mathrm{O}$. 2. Measurements and ab initio structures of negative ions. J. Phys. Chem. A 107, 9812-9824 (2003b)

P.L. Galison, Image and Logic: A Material Culture of Microphysics (University of Chicago Press, Chicago, 1997) 
D.R. Hanson, E.R. Lovejoy, Measurement of the thermodynamics of the hydrated dimer and trimer of sulfuric acid. J. Phys. Chem. A 110, 9525-9528 (2006)

R.G. Harrison, K.S. Carslaw, Ion-aerosol-cloud processes in the lower atmosphere. Rev. Geophys. 41 (2-1)(2-26), (2003)

R.G. Harrison, D.B. Stephenson, Empirical evidence for a nonlinear effect of galactic cosmic rays on clouds. Proc. R. Soc. A 462, 1221-1233 (2006)

U. Hõrrak, J. Salm, H. Tammet, Bursts of intermediate ions in atmospheric air. J. Geophys. Res. 103, 13909-13916 (1998)

R. Janson, H.-C. Rosman, K. Karlsson, A. Hansson, Biogenic emissions and gaseous precursors to forest aerosols. Tellus B 53(4), 423-440 (2001)

J. Kazil, E.R. Lovejoy, Tropospheric ionization and aerosol production: A model study. J. Geophys. Res. 109, D19206 (2004)

J. Kazil, E.R. Lovejoy, A semi-analytical method for calculating rates of new sulfate aerosol formation from the gas phase. Atmos. Chem. Phys. 7, 3447-3459 (2007)

J. Kazil, E.R. Lovejoy, M.C. Barth, K. O'Brien, Aerosol nucleation over oceans and the role of galactic cosmic rays. Atmos. Chem. Phys. 6, 4905-4924 (2006)

V.-M. Kerminen, T. Anttila, T. Petäjä, L. Laakso, S. Gagné, K.E.J. Lehtinen, M. Kulmala, Charging state of the atmospheric nucleation mode: Implications for separating neutral and ion-induced nucleation. J. Geophys. Res. 112, D21205 (2007)

T.O. Kim, T. Ishida, M. Adachi, K. Okuyama, J.H. Seinfeld, Nanometer-sized particle formation from $\mathrm{NH}_{3} / \mathrm{SO}_{2} / \mathrm{H}_{2} \mathrm{O} /$ Air mixtures by ionizing irradiation. Aer. Sci. Tech. 29, 111-125 (1998)

J.E. Kristjánsson, J. Kristiansen, Is there a cosmic ray signal in recent variations in global cloudiness and cloud radiative forcing? J. Geophys. Res. 105, 11851-11864 (2000)

J.E. Kristjánsson, A. Staple, J. Kristiansen, E. Kaas, A new look at possible connections between solar activity, clouds and climate. Geophys. Res. Lett. 29, 22-1 (2002)

J.E. Kristjánsson, J. Kristiansen, E. Kaas, Solar activity, cosmic rays, clouds and climate - an update. Adv. Space Res. 34, 407-415 (2004)

M. Kulmala, H. Vehkamäki, T. Petäjä, M. Dal Maso, A. Lauri, V.-M. Kerminen, W. Birmili, P.H. McMurry, Formation and growth rates of ultrafine atmospheric particles: A review of observations. J. Aer. Sci. 35, $143-176$ (2004a)

M. Kulmala, V.-M. Kerminen, T. Anttila, A. Laaksonen, C.D. O’Dowd, Organic aerosol formation via sulphate cluster activation. J. Geophys. Res. 109, D4205 (2004b)

M. Kulmala, A. Reissell, M. Sipilä, B. Bonn, T.M. Ruuskanen, K.E.J. Lehtinen, V.-M. Kerminen, J. Ström, Deep convective clouds as aerosol production engines: Role of insoluble organics. J. Geophys. Res. 111, 17202 (2006)

T. Kurtén, M. Noppel, H. Vehkamäki, M. Salonen, M. Kulmala, Quantum chemical studies of hydrate formation of $\mathrm{H}_{2} \mathrm{SO}_{4}$ and $\mathrm{HSO}_{4}^{-}$. Boreal Environ. Res. 12, 431-453 (2007)

L. Laakso, J.M. Mäkelä, L. Pirjola, M. Kulmala, Model studies on ion-induced nucleation in the atmosphere. J. Geophys. Res. 107, 4427 (2002)

L. Laakso, T. Anttila, K.E.J. Lehtinen, P.P. Aalto, M. Kulmala, U. Hõrrak, J. Paatero, M. Hanke, F. Arnold, Kinetic nucleation and ions in boreal forest particle formation events. Atmos. Chem. Phys. 4, 2353-2366 (2004a)

L. Laakso, T. Petäjä, K.E.J. Lehtinen, M. Kulmala, J. Paatero, U. Hõrrak, H. Tammet, J. Joutsensaari, Ion production rate in a boreal forest based on ion, particle and radiation measurements. Atmos. Chem. Phys. 4, 1933-1943 (2004b)

L. Laakso, S. Gagné, T. Petäjä, A. Hirsikko, P.P. Aalto, M. Kulmala, V.-M. Kerminen, Detecting charging state of ultra-fine particles: instrumental development and ambient measurements. Atmos. Chem. Phys. 7, 1333-1345 (2007a)

L. Laakso, T. Grönholm, L. Kulmala, S. Haapanala, A. Hirsikko, E.R. Lovejoy, J. Kazil, T. Kurtén, M. Boy, E.D. Nilsson, A. Sogachev, I. Riipinen, F. Stratmann, M. Kulmala, Hot-air balloon as a platform for boundary layer profile measurements during particle formation. Boreal Environ. Res. 12, 279-294 (2007b)

A. Laaksonen, V. Talanquer, D.W. Oxtoby, Nucleation: Measurements, theory, and atmospheric applications. Annu. Rev. Phys. Chem. 46, 489-524 (1995)

P.M. Langevin, Une formule fondamentale de théorie cinétique. Ann. Chim. Phys. 8, 245-288 (1905)

S.-H. Lee, J.M. Reeves, J.C. Wilson, D.E. Hunton, A.A. Viggiano, T.M. Miller, J.O. Ballenthin, L.R. Lait, Particle formation by ion nucleation in the upper troposphere and lower stratosphere. Science 301, 1886-1889 (2003)

E. Lovejoy, J. Curtius, Cluster ion thermal decomposition (II): Master equation modeling in the low pressure limit and fall-off regions. Bond energies for $\mathrm{HSO}_{4}^{-}\left(\mathrm{H}_{2} \mathrm{SO}_{4}\right)_{x}\left(\mathrm{HNO}_{3}\right)_{y}$. J. Phys. Chem. A 105, 10874 $10883(2001)$ 
E.R. Lovejoy, J. Curtius, K.D. Froyd, Atmospheric ion-induced nucleation of sulfuric acid and water. J. Geophys. Res. 109, D08204 (2004)

N. Marsh, H. Svensmark, Cosmic rays, clouds, and climate. Space Sci. Rev. 94, 215-230 (2000)

J.J. Marti, A. Jefferson, X. Ping Cai, C. Richert, P.H. McMurry, F. Eisele, $\mathrm{H}_{2} \mathrm{SO}_{4}$ vapor pressure of sulfuric acid and ammonium sulfate solutions. J. Geophys. Res. 102, 3725-3736 (1997a)

J.J. Marti, R.J. Weber, P.H. McMurry, F. Eisele, D. Tanner, A. Jefferson, New particle formation at a remote continental site: Assessing the contributions of $\mathrm{SO}_{2}$ and organic precursors. J. Geophys. Res. 102, 6331-6340 (1997b)

A.B. Nadykto, Yu, Uptake of neutral polar vapor molecules by charged clusters/particles: Enhancement due to dipole-charge interactions. J. Geophys. Res. 108, 4717 (2003)

A.B. Nadykto, A. Al Natsheh, F. Yu, K.V. Mikkelsen, R. J., Effect of molecular structure and hydration on the uptake of gas-phase sulfuric acid by charged clusters/ultrafine particles. Aer. Sci. Tech. 38, 349-353 (2004)

H.V. Neher, S.E. Forbush, Correlation of cosmic ray-intensity and solar activity. Phys. Rev. Lett. 1, 173-174 (1958)

P.A. O’Dowd, K. Hämeri, M. Kulmala, T. Hoffmann, Atmospheric particles from organic vapours. Nature 416, 497-498 (2002)

C. O'Dowd, P. Wagner, Nucleation and Atmospheric Aerosols (Springer, Berlin, 2008)

F. Raes, A. Janssens, Ion-induced aerosol formation in a $\mathrm{H}_{2} \mathrm{O}-\mathrm{H}_{2} \mathrm{SO}_{4}$ system-I. Extension of the classical theory and search for experimental evidence. J. Aer. Sci. 16, 217-227 (1985)

F. Raes, A. Janssens, Ion-induced aerosol formation in a $\mathrm{H}_{2} \mathrm{O}-\mathrm{H}_{2} \mathrm{SO}_{4}$ system-II. Numerical-calculations and conclusions. J. Aer. Sci. 17, 715-722 (1986)

F. Raes, A. Janssens, R. van Dingenen, The role of ion-induced aerosol formation in the lower atmosphere. J. Aer. Sci. 17, 466-470 (1986)

H. Reiss, The kinetics of phase transitions in binary systems. J. Chem. Phys. 18, 840-848 (1950)

W.B. Rossow, R.A. Schiffer, ISCCP Cloud data products. Bull. Am. Meteorol. Soc. 72, 2-20 (1991)

W.B. Rossow, R.A. Schiffer, Advances in understanding clouds from ISCCP. Bull. Am. Meteorol. Soc. 80, 2261-2287 (1999)

K. Sellegri, M. Hanke, B. Umann, F. Arnold, M. Kulmala, Measurements of organic gases during aerosol formation events in the boreal forest atmosphere during QUEST. Atmos. Chem. Phys. 5, 373-384 (2005)

T. Sloan, A.W. Wolfendale, Testing the proposed causal link between cosmic rays and cloud cover. Env. Res. Lett. 3, 024001 (2008)

J.N. Smith, K.F. Moore, F.L. Eisele, D. Voisin, A.K. Ghimire, H. Sakurai, P.H. McMurry, Chemical composition of atmospheric nanoparticles during nucleation events in Atlanta. J. Geophys. Res. 110, D22S03 (2005)

A. Sorokin, F. Arnold, D. Wiedner, Formation and growth of sulfuric acid-water cluster ions: Experiments, modelling, and implications for ion-induced aerosol formation. Atmos. Env. 40, 2030-2045 (2006)

T. Su, W.J. Chesnavich, Parametrization of the ion-polar molecule collision rate constant by trajectory calculations. J. Chem. Phys. 76, 5183-5185 (1982)

H. Svensmark, E. Friis-Christensen, Variation of cosmic ray flux and global cloud coverage-a missing link in solar-climate relationships. J. Atmos. Terr. Phys. 59, 1225-1232 (1997)

J.J. Thomson, Conduction of Electricity through Gases (Cambridge University Press, Cambridge, 1906)

R.P. Turco, J.-X. Zhao, F. Yu, A new source of tropospheric aerosols: Ion-ion recombination. Geophys. Res. Lett. 25, 635-638 (1998)

S.A. Twomey, The influence of pollution on the shortwave albedo of clouds. J. Atmos. Sci. 34, 1148-1152 (1977)

M. Vana, E. Tamm, U. Hõrrak, A. Mirme, H. Tammet, L. Laakso, P.P. Aalto, M. Kulmala, Charging state of atmospheric nanoparticles during the nucleation burst events. Atmos. Res. 82, 536-546 (2006)

K.G. Vohra, M.C. Subba Ramu, K.N. Vasudevan, Behavior of aerosols formed by clustering of molecules around gaseous ions. Atmos. Env. 3, 99-105 (1969)

M. Volmer, A. Weber, Keimbildung in übersättigten Gebilden. Z. Phys. Chem. 119, 277-301 (1926)

S. Wilhelm, S. Eichkorn, D. Wiedner, L. Pirjola, F. Arnold, Ion-induced aerosol formation: New insights from laboratory measurements of mixed cluster ions $\mathrm{HSO}_{4}^{-}\left(\mathrm{H}_{2} \mathrm{SO}_{4}\right)_{a}\left(\mathrm{H}_{2} \mathrm{O}\right)_{w}$ and $\mathrm{H}^{+}\left(\mathrm{H}_{2} \mathrm{SO}_{4}\right)_{a}\left(\mathrm{H}_{2} \mathrm{O}\right)_{w}$. Atmos. Env. 38, 1735-1744 (2004)

C.T.R. Wilson, Condensation of water vapour in the presence of dust-free air and other gases. Phil. Trans. R. Soc. of London A 189, 265-307 (1897)

C.T.R. Wilson, On the condensation nuclei produced in gases by the action of Röntgen rays, uranium rays, ultra-violet light, and other agents. Phil. Trans. R. Soc. of London A 192, 403-453 (1899)

B.E. Wyslouzil, J.H. Seinfeld, R.C. Flagan, K. Okuyama, Binary nucleation in acid-water systems. II. Sulfuric acid-water and a comparison with methanesulfonic acid-water. J. Chem. Phys. 94, 6842-6850 (1991) 
F. Yu, Altitude variations of cosmic ray induced production of aerosols: Implications for global cloudiness and climate, J. Geophys. Res. 107 (2002)

F. Yu, Modified Kelvin-Thomson equation considering ion-dipole interaction: Comparison with observed ion-clustering enthalpies and entropies. J. Chem. Phys. 122, 084503 (2005)

F. Yu, Binary $\mathrm{H}_{2} \mathrm{SO}_{4}-\mathrm{H}_{2} \mathrm{O}$ homogeneous nucleation based on kinetic quasi-unary nucleation model: Look-up tables. J. Geophys. Res. 111, D04201 (2006a)

F. Yu, Effect of ammonia on new particle formation: A kinetic $\mathrm{H}_{2} \mathrm{SO}_{4}-\mathrm{H}_{2} \mathrm{O}-\mathrm{NH}_{3}$ nucleation model constrained by laboratory measurements, J. Geophys. Res. 111 (2006b)

F. Yu, From molecular clusters to nanoparticles: second-generation ion-mediated nucleation model. Atmos. Chem. Phys. 6, 5193-5211 (2007)

F. Yu, R.P. Turco, Ultrafine aerosol formation via ion-mediated nucleation. Geophys. Res. Lett. 27, 883-886 (2000)

F. Yu, R.P. Turco, From molecular clusters to nanoparticles: Role of ambient ionization in tropospheric aerosol formation. J. Geophys. Res. 106, 4797-4814 (2001)

F. Yu, Z. Wang, G. Luo, R. Turco, Ion-mediated nucleation as an important global source of tropospheric aerosols. Atmos. Chem. Phys. 8, 2537-2554 (2008)

G.K. Yue, L.Y. Chan, Theory of the formation of aerosols of volatile binary-solutions through the ion-induced nucleation process. J. Coll. Int. Sc. 68, 501-507 (1979)

R. Zhang, I. Suh, J. Zhao, D. Zhang, E.C. Fortner, X. Tie, L.T. Molina, M.J. Molina, Atmospheric new particle formation enhanced by organic acids. Science 304, 1487-1490 (2004) 